\title{
IMPLEMENTASI PEMBELAJARAN TOILET TRAINING PADA ANAK AUTISM SPECTRUM DISORDER
}

\author{
Dinda Annisa Silvia, Juhanaini ${ }^{1}$, Asep Deni Gustiana ${ }^{2}$ \\ Program Studi Pendidikan Guru Pendidikan Anak Usia Dini, Departemen Pedagogik, \\ Fakultas Ilmu Pendidikan, Universitas Pendidikan Indonesia \\ Email :dindaannisa88@gmail.com
}

\begin{abstract}
Toilet training is an exercise using the bathroom properly and correctly. The presence of toilet training teaching will help a lot for those who have not mastered toilet training skills. this study aims to find out how the teacher in teaching Toilet training is intended for children Autism Spectrum Disorder. The research method used is descriptive method with qualitative approach. The location of the research was conducted at Kindergarten Bunda Ganesha Jl. Dark Nyawang No. 2 Bandung. The subject of this research is the teacher of Toilet training program instructor in the children of Autism Spectrum Disorder. The results of the toilet training study conducted an assessment first, after the results obtained by the teacher to analyze, the next step in preparing the program required by the child. To teach children, the teacher refers to the lesson plan and the material. That shows the pictures on how to use toilets and tools in the bathroom. The teacher gives direct instruction with lecture method and toilet training simulation and asks to practice it directly. teachers should often communicate with parents so that after being taught by the teacher after school can be continued at home.
\end{abstract}

Keyword: toilet training, child autism spectrum disorder

\begin{abstract}
Abstrak: Toilet training merupakan latihan menggunakan kamar mandi dengan baik dan benar. Adanya pengajaran toilet training akan banyak membantu bagi mereka yang belum menguasai keterampilan toilet training. penelitian ini bertujuan untuk mengetahui bagaimana cara guru dalam mengajarkan Toilet training yang diperuntukkan bagi anak Autism Spectrum Disorder. Metode penelitian yang digunakan adalah metode deskriptif dengan pendekatan kualitatif. Lokasi penelitian dilaksanakan di Taman Kanak-kanak Bunda Ganesa Jl. Gelap Nyawang No. 2 Bandung. Subjek penelitian adalah guru pelaksana program pengajaran Toilet training pada anak Autism Spectrum Disorder. Hasil penelitian pelaksanaan toilet training terlebih dahulu dilakukan assesmen, setelah hasilnya diperoleh guru menganalisa, langkah selanjutnya menyusun program yang dibutuhkan anak. Untuk mengajarkan kepada anak, guru mengacu pada RPP dan materinya. Yaitu menampilkan gambar-gambar mengenai tata cara menggunakan toilet dan alat-alat yang ada di kamar mandi. Guru memberi pengarahan secara langsung dengan metode ceramah dan simulasi toilet training dan menyuruh mempraktekannya secara langsung. guru harus sering berkomunikasi dengan orang tua agar setelah diajarkan guru setelah disekolah bisa dilanjutkan dirumah.
\end{abstract}

Kata Kunci: Toilet training, Anak Autism Spectrum Disorder

\section{PENDAHULUAN}

Anak Autism Spectrum Disorder merupakan anak yang mengalami gangguan perkembangan yang sangat kompleks, meliputi gangguan perilaku, interaksi, gangguan perkembangan yang mempengaruhi bahasa, interaksi sosial, umumya non verbal yang dapat diketahui dengan jelas sebelum usia 3 tahun, yang berpengaruh pada kinerja anak. karakteristik lain yang sering berhubungan dengan anak Autism Spectrum Disorder adalah keterlibatan dalam kegiatan berulang dan gerakan stereotip, perlawanan terhadap lingkungan atau dalam rutinitas sehari- 
hari, dan respon yang tidak biasa untuk pengalaman indrawi" (Hallahan dan Kauffman, 2009:425). Sedangkan pengertian lain diungkap oleh Hanafi (dalam Abdul Hadis, 2006: 43), autisme adalah gangguan perkembangan organik yang mempengaruhi kemampuan anakanak dalam berinteraksi dan menjalani kehidupannya.

Layanan yang dibutuhkan oleh anak Autism Spectrum Disorder agar dapat berkembang salah satunya dengan layanan pendidikan. Karena semua anak berhak mendapatkan pendidikan. Tidak terkecuali anak Autism Spectrum Disorder. Sesuai dengan Undang-Undang Dasar 1945 Pasal 31 (ayat 1) yang berbunyi "Setiap warga negara berhak mendapat pendidikan". Penyelenggaraan pendidikan untuk anak Autism Spectrum Disorder tentu tidak sama dengan anak pada umumnya. Penyelenggaraan pendidikan bagi anak Autism Spectrum Disorder sebaiknya adalah berorientasi kepada kebutuhan anak agar didapatkan hasil yang lebih fungsional.

Salah satu layanan pendidikan bagi anak Autism Spectrum Disorder di TK Bunda Ganesa adalah program bina diri. Menurut Astati (2003:15) mengatakan bahwa bina diri adalah "suatu usaha dalam membangun diri individu baik sebagai individu maupun makhluk sosial melalui pendidikan keluarga, di sekolah maupun di masyarakat, sehingga terwujud kemandirian dan keterlibatannya dalam kehidupan sehari-hari secara memadai". Tujuan akhir bina diri bagi anak Autism Spectrum Disorder pada dasarnya mengharapkan agar anak dapat mandiri dalam merawat diri. Salah satu program bina diri yang ada di TK Bunda Ganesa Bandung adalah pembelajaran bina diri toilet training pada anak Autism Spectrum Disorder bertujuan untuk mengembangkan kemandirian anak dalam hal toilet training. tidak semua anak Autism Spectrum Disorder yang bersekolah di TK Bunda Ganesa tersebut diberikan pembelajaran bina diri toilet training, sehingga menarik untuk diteliti sesuai pendapat guru bahwa hal ini dikarenakan pembelajaran bina diri yang ada di TK Bunda Ganesa didasarkan dari hasil asesmen, jadi setiap anak mendapatkan pembelajaran bina diri yang berbeda, sesuai kebutuhannya.

Berdasarkan hasil temuan di lapangan, peneliti menemukan kasus subjek A merupakan anak Autism Spectrum Disorder kelompok A berusia 4 tahun, berjenis kelamin laki-laki dengan karakteristik belum mampu berkomunikasi secara verbal dan mempunyai gangguan perhatian yang mengikuti pembelajaran bina diri toilet training di sekolah. Pembelajaran bina diri toilet training pada anak Autism Spectrum Disorder di TK Bunda Ganesa Bandung menarik untuk dideskripsikan.

Hal ini dikarenakan program bina diri toilet training diselenggarakan oleh sekolah tersebut untuk anak Autism Spectrum Disorder yang mana anak Autism Spectrum Disordertersebut belum mampu berkomunikasi secara verbal dan mengalami gangguan perhatian, sehingga akan timbul sebuah pertanyaan bagaimana cara mengajarkannya dan menjadi unik untuk dideskripsikan. Selain itu pembelajaran bina diri toilet training terselenggara dengan baik, mampu membekali anak Autism Spectrum Disorder dalam hal merawat diri sendiri sehingga mengurangi ketergantungannya dengan orang lain dan belum dideskripsikan secara rinci pelaksanaannya yang mencakup persiapan pembelajaran, pelaksanaan pembelajaran, dan evaluasi pembelajaran, serta faktor penghambat pembelajaran bina diri toilet training.

\section{METODE \\ Jenis Penelitian}

Penelitian ini merupakan penelitian deskriptif dengan pendekatan 
kualitatif. Menurut Tohirin (2012: 3) penelitian kualitatif adalah suatu penelitian fenomena tentang apa yang dialami oleh subjek penelitian misalnya perilaku, persepsi, motivasi, tindakan dan lain-lain secara holistik dan dengan cara deskripsi dalam bentuk kata-kata dan bahasa pada suatu konteks khusus yang alamiah. Penelitian deskriptif adalah penelitian yang menggambarkan secara jelas tanpa ada perlakuan terhadap objek yang diteliti. Penelitian ini menggunakan pendekatan kualitatif karena peneliti bermaksud untuk mendeskripsikan gambaran secara lebih rinci mengenai pembelajaran bina diri toilet training pada anak Autism Spectrum Disorder di TK Bunda Ganesa Bandung, yang meliputi persiapan pembelajaran, pelaksanaan pembelajaran, evaluasi pembelajaran dan faktor penghambat pembelajaranbina diri toilet training pada anak Autism Spectrum Disorder di TK Bunda Ganesa Bandung.

\section{Waktu dan Tempat Penelitian}

Penelitian ini dilakukan di TK
Bunda Ganesa beralamatkan di Jl. Gelap Nyawang No. 2, Bandung. Waktu penelitian dilaksanakan pada bulan Januari Februari 2016.

\section{Target / Subjek Penelitian}

Subjek penelitian dari penelitian ini adalah anak Autism Spectrum Disorder kelompok A di TK Bunda Ganesa Bandung dan guru kelas yang mengampu pembelajaran bina diri toilet training di TK Bunda Ganesa Bandung. Karakteristik anak berjenis kelamin lakilaki, berusia 4 tahun, belum mampu berkomuniksi secara verbal dan mempunyai gangguan perhatian yang mengikuti pembelajaran bina diri toilet training di sekolah.

\section{Prosedur}

Penelitian dilakukan dengan penyusunan proposal penelitian yang berdasarkan observasi awal di lapangan. Selanjutnya, setelah proposal selesai peneliti membuat instrument pelaksanaan dan melakukan pengumpulan data dilakukan dengan teknik observasi, wawancara dan dokumentasi. Data penelitian diperoleh melalui teknik pengumpulan data yang digunakan disertai dengan pedoman observasi dan pedoman wawancara. Pengolahan data dilakukan sejak awal pengambilan data hingga akhir pengumpulan data. Hasil olahan data disajikan ke dalam hasil penelitian.

\section{Teknik Pengumpulan Data}

Pengumpulan data dilakukan dengan menggunakan metode observasi, wawancara dan dokumentasi. Teknik pengumpulan data ini bertujuan untuk mengumpulkan data terkait dengan pembelajaran toilet training pada anak Autism Spectrum Disorder di TK Bunda Ganesa Bandung, yang meliputi persiapan pembelajaran, pelaksanaan pembelajaran, evaluasi pembelajaran dan faktor penghambat pembelajaran bina diri toilet training pada anak Autism Spectrum Disorder di TK Bunda Ganesa Bandung.

\section{Analisis Data}

Data yang diperoleh dianalisis degan cara reduksi data, display data dan pengagambilan keputusan, serta keabsahan data. Data penelitian yang diperoleh di reduksi dengan cara merangkum, memilih hal yang pokok, memfokuskan pada hal yang penting dicari tema dan polanya serta membuang hal yang tidak relevan dengan tujuan dan masalah penelitian. Selanjutnya dibahas dan disajikan dalam display data. Data penelitian yang telah di bahas keterkaitannya antara tujuan dengan hasil penelitian, kemudian ditarik kesimpulan sehingga dapat diketahui hasil dari pembelajaran toilet training pada anak Autism Spectrum Disorder yang 
dilaksanakan TK Bunda Ganesa Bandung.

Keabsahan data menggunakan triangulasi metode. Penerapan triangulasi metode yaitu dengan menggunakan metode observasi. Peneliti melakukan pengamatan selama pembelajaran toilet training mengenai persiapan pembelajaran, evaluasi pembelajaran dan faktor penghambat dalam pembelajaran bina diri toilet training pada anak Autism Spectrum Disorder. Berdasarkan data hasil observasi yang telah diperoleh, kemudian peneliti melakukan cross check dengan data hasil wawancara terhadap guru dan dokumentasi.

\section{HASIL DAN PEMBAHASAN}

Pembelajaran bina diri toilet training merupakan salah satu realisasi program bina diri yang dijalankan oleh TK Bunda Ganesa Bandung. Tujuan dari pembelajaran bina diri toilet training adalah untuk membekali peserta didik dalam hal merawat dirinya sendiri, mencakup mandi, gosok gigi, berpakaian dengan harapan anak sedikit demi sedikit mempunyai kemampuan toilet training yang baik sehingga dapat mengurangi ketergantungannya dengan orang lain. Sesuai hasil wawancara dengan guru kelas dan hasil observasi, bahwa pemberian program bina diri toilet training berdasarkan hasil asesmen yang dilakukan guru, yang mana subjek memang membutuhkan pembelajaran bina diri toilet training agar kemampuan toilet training-nya baik dan tidak bergantung kepada orang tua di rumah ataupun dengan guru pada saat di sekolah. Asesmen dilakukan pada awal anak masuk di sekolah tersebut dan dilakukan secara berkala pada setiap awal semester. Dalam pelaksanaan pembelajaran bina diri toilet training ada tahap persiapan, pelaksanaan serta evaluasi.
1. Persiapan Pembelajaran Toilet

Training pada Anak Autism Spectrum Disorder

Berdasarkan hasil observasi dan wawancara yang dilakukan peneliti, diperoleh data mengenai persiapan pembelajaran bina diri toilet training yang dilakukan oleh guru kelas pada awalnya adalah melakukan asesmen yaitu kegiatan sistematis untuk mengumpulkan informasi, menemukenali kondisi, kemampuan,serta kebutuhan belajar anak Autism Spectrum Disorder guna menyusun program pembelajaran yang sesuai. Hasil asesmen menunjukkan kemampuan bina diri anak masih rendah, belum mampu toilet training secara mandiri. Asesmen dilakukan pada pertama kali anak masuk di sekolah,namun untuk memberikan program yang lebih tepat lagi asesmen lanjutan dilakukan setiap awal semester.

Sesuai hasil asesmen yang didapatkan, guru menetapkan suatu program untuk mengembangkan kemandirian anak, yaitu bina diri toilet training. Program bina diri tersebut dimasukkan dalam suatu pembelajaran yang disebut pembelajaran bina diri toilet training dengan tujuan pembelajaran yaitu mengembangkan kemandirian anak terkait toilet training merupakan suatu kebutuhan individu yang setiap hari dilakukan. Tujuan pembelajaran disesuaikan dengan hasil asesmen yaitu mengenai kemandirian anak, kemampuan toilet training anak yang masih belum baik. Berdasarkan hasil asesmen yang dilakukan guru didapatkan hasil bahwa subjek memang membutuhkan program bina diri toilet training agar kemandiriannya lebih baik. Selanjutnya setelah melakukan asesmen, pembelajaran dilanjutkan dengan guru menyusun Rencana Pelaksanaan Pembelajaran (RPP). 
2. Pelaksanaan Pembelajaran Toilet Training pada Anak Autism Spectrum Disorder.

Berdasarkan hasil observasi dan wawancara yang dilakukan peneliti, diperoleh data mengenai pelaksanaan pembelajaran toilet training pada anak Autism Spectrum Disorder di Taman kanak-kanak Bunda Ganesa. Pelaksanaan pembelajaran toilet training dilakukan melalui langkah pembelajaran yang berupa pendahuluan, kegiatan inti, dan penutup/ kegiatan akhir yang dapat dideskripsikan sebagai berikut :

a. Pendahuluan

Pembelajaran diawali dengan mengkondisikan anak di kelas setelah istirahat kedua sudah selesai. Setelah anak sudah terkondisikan selanjutnya guru memberikan apersepsi dengan menunjukkan gerakan tangan atau isyarat toilet training pertanda bahwa saatnya pembelajaran toilet training. Hal ini dikarenakan anak belum mampu berkomunikasi secara verbal dengan guru, melainkan dengan menggunakan gerakan-gerakan tertentu. Apresepsi diperjelas dengan pejelasan guru secara lisan yang mengungkapkan materi pembelajaran selanjutnya adalah toilet training dan tujuanny agar anak mampu toilet training dengan baik. Karena peserta didiknya adalah anak Autism Spectrum Disorder, penyampaian materi dan tujuan pembelajaran juga sangat singkat lugas dan jelas. Pernyataan guru pada saat itu

"kaa, kita ke kamar mandi yuk, kaka mau pipis atau pup tidak"

b. Kegiatan Inti

Kegiatan inti pembelajaran toilet training pada anak Autism Spectrum Disorder adalah guru menyampaikan materi yang terdiri dari fungsi toilet training dan tahapan-tahapan toilet training kemudian guru membimbing anak untuk mempraktekan toilet training sesuai tahapan-tahapan. Materi yang pertama disampaikan adalah fungsi toilet training, dalam pembelajaran ini guru menjelaskan kepada anak bahwa fungsi toilet training adalah agar terbentuknya kemandirian anak. setelah itu dilanjutkan pengertian alat-alat di kamar mandi dan kegunaannya. Alat yang di kamar mandi yang dimaksud meliputi gayung, ember, dan sabun. Guru memberikan penjelasan kepada anak mengenai peralatan-peralatan tersebut satu persatu beserta fungsinya. Pada saat itu, guru mengambil gayung dan mengatakan kepada anak "GAYUNG" sambil mensimulasikan gerakan menyiram menggunakan gayung. Guru mengambil sabun dan mengatakan pada anak "SABUN". Setelah semua peralatan diidentifikasikan nama dan kegunaanya kemudian guru mengetes anak dengan cara meminta anak menunjuk benda yang ditanyakan. Guru mengatakan "AMBIL SABUN". Dengan bantuan guru anak mengambil sabun yang berada di atas meja bersama dengan peralatan-peralatan toilet training yang lain. Setelah mampu mengambil benda yang diminta guru. Kemudian guru menjelaskan tahapan-tahapan toilet training dengan cara mensimulasikan dengan sebuah gerakan. Guru juga meminta anak untuk menirukan gerakangerakan guru. Setelah selesai guru mengajak anak pergi ke kamar mandi untuk mempraktekkan toilet training sesuai tahapan-tahapannya.

Pada kegiatan inti selanjutnya dari pembelajaran toilet training pada anak Autism Spectrum Disorder adalah guru membimbing anak untuk mempraktekan toilet training sesuai 
dengan tahapan-tahapan, sebagai berikut :

a. Guru membimbing anak untuk masuk ke dalam kamar mandi

b. Guru meminta anak untuk melepas pakaian dengan kata-kata yang jelas, dimulai dari celana, celana dalam. Anak belum melakukan yang diminta guru, maka instruksinya lagi "BUKA" setelah sampai tiga kali intruksi anak belum melakukan, guru memberikan prompt

c. Guru meminta anak meletakkan celana di gantungan/kapstok. Dengan cara isyarat menunjuk pakaian anak yang sudah dilepas dan menunjuk kapstok yang ada di kamar mandi dan mengatakan "GANTUNGKAN"

d. Guru membimbing anak membiasakan duduk di closet ketika buang air besar atau buang air kecil dengan intruksi "DUDUK"

e. Guru meminta anak untu membersihkan diri setelah buang air besar atau buang air kecil. Dalam tiga kali instruksi anak belum membersihkan diri atau cebok dengan benar, maka guru memberikan prompt

f. Guru meminta anak untuk menyiram closet setelah buang air besar atau buang air kecil dengan cara guru berkata "SIRAM"

g. Guru membimbing anak untuk memakai pakaian dimulai dari celana dalam dan celana. Pada awalnya guru hanya menginstruksikan saja dengan mengatakan "PAKAI" sambil memberikan celana anak, namun setelah tiga kali instruksi anak tidak melakukan kegiatan yang diinginkan, maka guru memberikan bantuan dengan cara memakai celana anak.

c. Penutup

Kegiatan akhir dari pembelajaran toilet training adalah guru memberi tugas kepada anak untuk mencuci tangan dan mengelap tangan sesudah melakukan toilet training. Anak mampu melaksanakan tugas, maka mendapatkan reward "Toss' dari guru. Kemudian guru membimbing anak untuk kembali ke kelas. Setelah itu guru mengevaluasi pembelajarannya yang telah dilaksanakan.

\section{Evaluasi Pembelajaran Toilet Training} pada Anak Autism Spectrum Disorder. Evaluasi penyelenggaraan program bina diri toilet training yang tersusun dalam suatu pembelajaran di Taman kanak-kanak Bunda Ganesa berguna untuk mengetahui keberhasilan pembelajaran tersebut. Evaluasi yang digunakan guru berupa evaluasi tes dan non tes. Evaluasi meliputi sikap anak mengikuti pembelajaran dan mengikuti semua instruksi dari guru, serta kemampuannya melaksanakan tahapantahapan toilet training. Evaluasi tes digunakan guru pada saat meminta anak mengidentifikasikan peralatan toilet training. Evaluasi non tes digunakan guru pada saat mengamati proses pembelajaran bina diri toilet training berlangsung kemudian dicatat dalam sebuah buku. Hasil dari evaluasi berguna untuk meningkatkan pembelajaran, dan memperbaiki hal-hal yang masih dianggap belum berhasil atau belum mencapai target. Guru biasanya membuat catatan pada setiap pembelajaran bina diri toilet training dalam buku, jadi setiap selesai pembelajaran yang dilaksanakan kemudian dicatat untuk mengetahui dan melihat kemampuan anak dalam hal toilet training. Hal tersebut diungkapkan oleh guru kelas bahwa :

"Setiap selesai pembelajaran toilet training ini selalu dicatat, apa yang anak belum bisa. Kadang susah kalau disuruh menyiram, pernah juga anak menyiram sudah bisa. Pakai celana anak kadang masih kesulitan. Jadi semua itu perlu dicatat biar tau perkembangannya" 
Selain mencatat setiap kemampuan yang dimiliki anak, evaluasi pembelajaran ini juga dilakukan dengan rapat bersama dengan orang tua anak. rapat biasanya dilakukan pada saat penerimaan rapot. Di mana saat itu guru bersama dengan orang tua anak membicarakan perkembangan anak, termasuk dalam hal kemandirian.

4. Faktor penghambat dalam Pembelajaran Toilet Training pada Anak Autism Spectrum Disorder.

Dalam pelaksanaan kegiatan pembelajaran toilet training pada anak Autism Spectrum Disorder, tentunya tidak terlepas dari faktor penghambat kegiatan pembelajaran yang akan berpengaruh pada keberhasilan pembelajaran yang dilaksanakan. Kendala atau masalah belajar baik intern maupun ekstern dapat dikaji dari dimensi guru maupun dimensi anak, sedangkan dikaji dari tahapannya masalah belajar dapat terjadi pada waktu sebelum kegiatan pembelajaran, selama proses belajar dan sesudah kegiatan pembelajaran.

Melalui hasil wawancara dengan guru dapat diungkap bahwa faktor penghambat dalam pembelajaran toilet training ini adalah sebagai berikut :

a. Faktor Internal

Menurut guru, anak Autism Spectrum Disorder yang saat ini sedang ditangani termasuk berat sehingga menghambat keberhasilan pembelajaran. Akan tetapi guru berusaha semaksimal mungkin untuk mengembangkan kemandirian anak. selain derajat gangguan Autism Spectrum Disorder yang disandang anak tergolong berat, kemampuan berbicara dan berkomunikasi anak juga belum baik yang mana ini tentunya menghambat keberhasilan pembelajaran toilet training. karena semakin anak Autism Spectrum Disorder memiliki kemampuan berbicara dan berbahasa yang lebih baik tentunya tingkat keberhasilannya akan lebih cepat dan lebih baik. Terlebih lagi anak masih kadangkadang keadaan emosinya tidak stabil.

b. Faktor Eksternal

Faktor eksternal yang menghambat keberhasilan pembelajaran toilet training menurut wawancara guru adalah sikap orang tua yang masih memanjakan anak saat di rumah, selalu melayani keinginan anak. dengan kondisi yang seperti itu, maka kemandirian anak akan terhambat, tidak bisa berkembang. Karena pembelajaran di sekolah membutuhkan dukungan juga dari pihak keluarga.

\section{Pembahasan}

Berdasarkan analisis data di atas, pembelajaran bina diri toilet training yang diselenggarakan Taman kanakkanak Bunda Ganesa bertujuan untuk mengembangkan kemandirian anak dalam hal toilet training dengan harapan anak sedikit demi sedikit mempunyai kemampuan teoilet training yang baik sehingga dapat mengurangi ketergantungan dengan orang lain. Tujuan ini sama halnya dengan pendapat dari Astati (2011: 8) bahwa tujuan bina diri adalah "untuk mengembangkan keterampilan dasar dalam memlihara dan memenuhi kebutuhan anak tunagrahita sehingga dapat hidup mandiri dengan tidak / kurang bergantung pada orang lain dan mempunyai tanggung jawab sesuai dengan kemampuannya baik sebagai makhluk individu maupun sebagai makhluk sosial". Anak Autism Spectrum Disorder dengan anak tuna grahita samasama memiliki kemandirian yang kurang maka tujuan diberikannya pembelajaran bina diri adalah untuk membekali kemandirian mereka sehingga mengurangi ketergantuan dengan orang lain. 
Selanjutnya setelah melakukan asesmen, persiapan pembelajaran dilanjutkan dengan guru menyusun Rencana Pelaksanaan Pembelajaran (RPP) yang mencakup perencanaan tujuan, materi, metode, media, dan evaluasi pembelajaran.

Pelaksanaan pembelajaran toilet training pada anak Autism Spectrum Disorder di TK Bunda Ganesa Bandung sudah sesuai dengan pendapat Darmawan, D. dan Permasih (2011: 133) yang menyebutkan bahwa proses belajar meliputi kegiatan awal hingga akhir pembelajaran yang meliputi :1) kegiatan awal berupa apersepsi, penyampaian tujuan pembelajaran maupun pretest. 2) kegiatan inti merupakan aktivitas pemberian materi melalui berbagai strategi dan metode. 3) kegiatan akhir yaitu menyimpulkan pembelajaran. Karena di dalam pelaksanaan pembelajaran bina diri toilet training sudah meliputi kegiatan awal, kegiatan inti dan penutup.

Pelaksanaan pembelajaran bina diri toilet training pada anak Autism Spectrum Disorder di Taman kanakkanak Bunda Ganesa Bandung dapat dipahami berbeda dengan pembelajaran bina diri untuk anak pada umumnya, pelaksanaan pembelajaran ini disesuaikan dengan kondisi anak yaitu menggunakan metode Aplied Behavior Analysis (ABA). Terapi ABA adalah metode tatalaksana perilaku yang berkembang sejak puluhan tahun, ditemukan psikolog Amerika, Universitas California Los Angeles, Amerika Serikat, Ivar O. Lovaas (Handojo, 2008: 15), sehingga banyak orang yang telah menggunakan istilah "Lovaas Therapy" atau "Lovaas Method" untuk "Intensive Behavior Treatment" (IBI).

$$
\text { Ivaar Lovaas telah }
$$

mengembangkan tatalaksana perilaku untuk anak-anak Autism Spectrum Disorder. Dasar pemikiran tatalaksana perilaku, yaitu perilaku yang diinginkan maupunyang tidak diinginkan bisa dikontrol atau dibentuk dengan system reward dan punishment. Pemberian reward akan meningkatkan frekuensi munculnya perilaku yang diinginkan, sedangkan punishment akan menurunkan frekuensi munculnya perilaku yang tidak diinginkan. Reward yang diberikan guru dalam pembelajaran toilet training ini berupa pujian dan "toss" apabila anak mengikuti instruksi yang diberikan guru. Metode pengajaran yang digunakan adalah DDT (Discrete Trial Training) yaitu metode yang berstruktur menuruti pola tertentu dan bisa ditentukan awal dan akhirnya. DDT terdiri dari instruktur, prompt, respon, konsekuensi dan interval waktu antara instruksi yang satu dengan instruksi yang lain. Intruksi yang digunakan guru pada saat pembelajaran bina diri toilet training menggunakan kata-kata yang singkat jelas dan lugas dengan intonasi yang sama sehingga anak dapat lebih mudah memahaminya.

$$
\text { Evaluasi penyelenggaraan }
$$
program bina diri toilet training yang tersusun dalam suatu pembelajaran di Taman kanak-kanak Bunda Ganesa Bandung berguna untuk mengetahui keberhasilan pembelajaran tersebut. Menurut Sudjana (2006: 9-10) penilaian (evaluating) adalah kegiatan mengumpulkan, mengolah dan dan menyajikan data untuk masukan dalam pengambilan keputusan mengenai program yang sedang dan atau telah dilaksanakan. Evaluasi tes dilakukan pada saat praktik toilet training, anak mampu membedakan peralatan-peralatan toilet training apa tidak. Sedangkan evaluasi non tes dilakukan dengan mengamati kemampuan anak pada saat mempraktikkan toilet training kemudian setelah selesai pembelajaran dicatat dalam sebuah buku catatan.

Tingkat keberhasilan pelaksanaan pendidikan dan pengajaran bagi anak Autism Spectrum Disorder dipengaruhi oleh beberapa faktor. Menurut Azwandi, 
Y. (2005: 158), faktor yang mempengaruhi pembelajaran anak Autism Spectrum Disorder adalah :

1. Berat ringannya kelainan/ gejala Autism Spectrum Disorder yang dialami anak, anak Autism Spectrum Disorder yang derajat gangguannya berat akan lebih lambat mencapai keberhasilan dibandingkan yang lebih ringan gangguannya. Jadi semakin ringan tingkat gangguan Autism Spectrum Disorder yang dialami anak, maka kemungkinan keberhasilan menjasi lebih cepat dan lebih baik.

2. Usia pada saat diagnosis dilakukan. Semakin dini usia anak ketika dilakukan diagnosis, maka program penyembuhan dan program pendidikan biasanya lebih menunjukkan keberhasilan dan sebaliknya semakin lambat dilaksanakan diagnosis maka semakin sulit atau berat mencapai keberhasilan.

3. Tingkat kemampuan bicara dan bahasa. Anak Autism Spectrum Disorder yang memiliki kemampuan berbicara dan berbahasa yang lebih baik tentunya tingkat keberhasilannya akan lebih cepat dan lebih baik.

Dalam pelaksanaan pembelajaran bina diri toilet training pada anak Autism Spectrum Disorder, tentunya tidak terlepas dari faktor penghambat kegiatan pembelajaran yang akan berpengaruh pada keberhasilan pembelajaran yang dilaksanakan. Faktor penghambat dalam pembelajaran bina diri toilet training pada anak Autism Spectrum Disorder di Taman kanak-kanak Bunda Ganesa Bandung ini adalah sebagai berikut :

a. Faktor Internal

Subjek merupakan anak Autism Spectrum Disorder tipe berat, kemampuan berbicara dan berkomunikasi anak juga belum baik yang mana ini tentunya menghambat

keberhasilan

pembelajaran bina diri toilet training. terlebih lagi anak masih kadang-kadang keadaan emosinya tidak stabil.

b. Faktor Eksternal

Faktor eksternal yang menghambat keberhasilan pembelajaran bina diri toilet training adalah sikap orang tua yang masih memanjakan anak saat di rumah, selalu melayani keinginan anak. Dengan kondisi yang seperti itu, maka kemandirian anak akan terhambat, tidak bisa berkembang.

Dari faktor penghambat yang ditemui dalam pembelajaran bina diri toilet training pada anak Autism Spectrum Disorder di Taman kanak-kanak Bunda Ganesa Bandung maka dapat disimpulkan bahwa pembelajaran bina diri toilet training pada anak Autism Spectrum Disorder dapat dilhat keberhasilannya apabila dijalankan secara kontinyu dan konsisten. Pembelajaran ini dilakukan setiap hari, sesuai dengan pendapat salah satu guru yang mengajar di Taman kanak-kanak Bunda Ganesa Bandung, bahwa pembelajaran bina diri lebih ditekankan pada pembiasaan kepada anak didiknya.

\section{SIMPULAN DAN REKOMENDASI}

\section{SIMPULAN}

Implementasi pembelajaran bina diri toilet training pada anak Autism Spectrum Disorder di Taman kanakkanak Bunda Ganesa Bandung,ditarik kesimpulan sebagai berikut :

1. Pembelajaran bina diri toilet training yang dilaksanakan di Taman kanakkanak Bunda Ganesa Bandung memiliki tujuan umum untuk mengembangkan kemandirian anak Autism Spectrum Disorder dalam hal 
toilet training. Dan tujuan khusus a) anak mampu mengerti fungsi toilet training, b) anak mampu mengerti peralatan-peralatan yang ada di kamar mandi meliputi sabun, gayung, sikat gigi dan pakaian, c) anak mampu mengerti kegunaan peralatan-peralatan kamar mandi, d) anak mampu mengerti tahapantahapan toilet training dengan benar

2. Persiapan pembelajaran bina diri toilet training diawali dengan guru melakukan asesmen terhadap anak, dilanjutkan dengan menentukan program yang sesuai dengan hasil asesmen kemudian menyusun RPP.

3. Pelaksanaan pembelajaran bina diri toilet training pada anak Autism Spectrum Disorder dilaksanakan melalui 3 tahapan :

a. Pendahuluan / Kegiatan Awal Pembelajaran dimulai dengan pengkondisian anak di kelas. Selanjutnya guru memberi apersepsi dan menyampaikan materi dan tujuan pembelajaran dengan singkat lugas dan jelas.

b. Kegiatan Inti

$$
\text { Kegiatan }
$$

inti

pembelajaran bina diri toilet training yaitu guru menyampaikan materi toilet training, fungsi toilet training, peralatan dan tahap-tahapan toilet training dengan menggunakan metode ceramah dan metode simulasi. Kemudian mengajak dan membimbing anak masuk kamar mandi. Selanjutnya membimbing dan menginstruksikan anak untuk toilet training sesuai tahapantahapannya. Apabila dalam 3 kali instruksi anak tidak mampu melaksanakan, maka guru memberikan prompt.

c. Penutup / Kegiatan Akhir Penutup pembelajaran bina diri toilet training dilakukan dengan guru meminta anak untuk mencuci tangan dan mengelap tangan sesudah melakukan toilet training dan membimbing anak untuk kembali ke kelas. lalu

4. Evaluasi pembelajaran bina diri toilet training pada anak Autism Spectrum Disorder meliputi evaluasi tes dan non tes.

5. Factor penghambat dalam pembelajaran toilet training meliputi factor internal yaitu anak tergolong Autism Spectrum Disorder yang berat, mempunyai kemampuan berbicara dan berkomunikasi belum baik dan factor eksternal yaitu dukungan keluarga yang kurang Karena selalu melayani dan memanjakan anak di rumah.

\section{REKOMENDASI}

1. Bagi Guru

a. Diharapkan pada kegiatan evaluasi pembelajaran bina diri toilet training disediakan instrument yang disusun secara sistematis, sehingga setiap aspek tahapan-tahapan toilet training yang dipelajari anak Autism Spectrum Disorder lebih dapat terlihat perkembangannya.

b. Hendaknya guru dengan orang tua anak lebih menjalin hubungan yang baik dalam rangka mengembangkan kemandirian anak.

2. Bagi Orang Tua
a. Sebaiknya orang tua tidak memanjakan anak pada saat di rumah, agar anak belajar mandiri.
b. Diharapkan langkah pembelajaran bina diri toilet training dapat diterapkan di rumah.

3. Bagi Peneliti Selanjutnya

Diharapkan bagi penelitian selanjutnya lebih memperluas wilayah generalisasi, tidak hanya bagi anak Autism Spectrum Disorder seperti subjek dalam penelitian ini 
sehingga manfaat penelitian yang di dapat lebih banyak.

\section{Daftar Rujukan}

Abdul, Hadis. (2006). Pendidikan Anak Berkebutuhan Khusus Autistik. Bandung : Alfabeta

Astati dkk, (2003). Program Khusus Bina Diri Bisakah aku Mandiri. Jakarta: Departemen Pendidikan Nasional Direktorat Pendidikan Dasar dan Menengah Direktorat Pembinaan Pendidikan Luar Biasa.

Astati. (2011). Bina Diri Untuk Anak Tunagrahita, Edisi kedua. Bandung: Amanah Offset.

Azwandi, Yosfan. (2005). Mengenal dan Membantu Penyandang Autis. Jakarta: Departemen Pendidikan Nasional.

Darmawan, D. \& Permasih. (2011). Kurikulum \& Pembelajaran. Jakarta: Rajawali Pers.

Sudjana, D. (2006). Pendidikan Nonformal (Wawasan, Sejarah,Perkembangan Filsafat, Teori Pendukung Asas). Bandung: Falah Production.

Hallahan, D.P. \& Kauffman, J.M. (1988). Exceptional Children. Virginia: Prentice hall International, Inc

Handojo. (2008). Autisma. Jakarta: PT. Bhuana Ilmu Populer.

Tohirin. (2013). Metode Penelitian Kualitatif dalam Pendidikan dan Bimbingan Konseling. Jakarta: PT RajaGrafindo Persada. 